DOI 10.37882/2223-2982.2021.06-2.16

\title{
УНИВЕРБАЦИЯ В АНГЛИЙСКОЙ СИСТЕМЕ КОМПРЕССИВНЫХ СЛОВООБРАЗОВАТЕЛЬНЫХ ТИПОВ И ФУНКЦИОНИРОВАНИЕ УНИВЕРБОВ В ПРЕССЕ
}

\section{UNIVERBATION IN THE ENGLISH SYSTEM OF COMPRESSIVE WORD-FORMATION TYPES AND FUNCTIONING OF UNIVERBS IN THE PRESS}

R. Konev

Summary: The topicality of the study is due to the fact that in modern languages the tendency towards regularity is actively developing, which is expressed in the human desire to reduce the complex structure of a word to a simpler one for successful communication. Thus, wordformation compression is one of the most effective techniques of modern word formation, which allows a person to convey more information in a much shorter period of time.

The aim of this work is to study and analyze types of univerbation and models of univerbs in the context of lexical units and their combinations in English.

Realization of the foregoing aim is achieved by the solution of the following attendant tasks:

- determination of motivational features of the univerbation and their lexico-thematic groups;

- definition of the terms univerbation, univerb and identification of their functioning in the context of structural compression of language units in English

- consideration the need, validity and perspectivity of univerbation in the English communicative culture.

Keywords: univerbation, univerbs, structural compression, the principle of economy of speech means, word-formation.

\author{
Конев Роман Евгеньевич \\ Новосибирский государственный университет \\ konevre@mail.ru
}

Аннотация: Актуальность исследования обусловлена тем, что в современных языках активно развивается тенденция к регулярности, которая выражается в стремлении человека свести сложную структуру слова к более простой для успешной коммуникации. Таким образом, словообразовательная компрессия является одним из наиболее эффективных приемов современного словообразования, позволяющим человеку передать больше информации за гораздо меньший промежуток времени.

Целью данной работы является рассмотрение и анализ типов универбов и моделей универбации в контексте структурной компрессии лексических единиц и их сочетаний в английском языке.

Реализация поставленной цели достигается путем решения следующих сопутствующих задач:

- определение мотивационных особенностей универбации с систематизацией ее моделей;

- определение терминов универбация, универб и выявление их функционирования;

- рассмотрение необходимости, обоснованности и перспективности универбации в английской коммуникативной культуре.

Ключевые слова: универбация, универбы, структурная компрессия, экономия речевых единиц, словообразование.
$\mathrm{T}$ ермин «универбация» восходит к латинскому слову «unumverbum», что означает «одно слово», и, как отмечает Н.С. Валгина, впервые он был использован в 1904 году немецким лингвистом К. Бругманом [1, С. 130]. Однако основу формирования теории универбации, по мнению Л.В. Копоть, заложил польский лингвист Ю. Розвадовский $[2$, С. 5]. В дальнейшем его идеи были успешно развиты в 50-60-е годы XX в. в работах В.В. Виноградова и А.В. Исаченко. Многие другие известные лингвисты, такие как 3.К. Ахметжанова, Т.Г. Винокур, И.П. Глотова, М. Докулил, В.В. Лопатин, В.М. Мокиенко, Д.Н. Шмелев, Н.А. Янко-Триницкая и другие также внесли значительный вклад в развитие теории универбации в 70-80-е годы прошлого века. В настоящее время теория универбация тщательно изучается Ж.А. Лазареврй, Л.И. Осиповой, И.А. Устименко и др.
В настоящее время определение термина «универбация» остается сложным и спорным. По мнению Л.И. Осиповой, универбация - это такой способ образования слов на базе словосочетания, при котором производное слово включает в себя основу только одного члена словосочетания, поэтому производное соотносится со словом по форме, и со всем словосочетанием по смыслу [3, С. 52]. Н.Ф. Алефиренко понимает универбацию как образование новых слов в результате семантического сжатия фразы и выделения одного из ее компонентов [4, C. 101].

С.В. Гудилова определяет универбацию как один из продуктивных способов компрессивного словообразования, средство конденсации многословных имен, с помощью которого создаются вторичные компрессиро- 
ванные именные единицы [5, С. 23].

М. Докулил относит универбацию к преобразованию уже существующих многословных наименований в однословные [6, С. 34].

3.К. Ахметжанова определяет универбацию как «процесс возникновения одного лексемного обозначения (универб) из предшествующего описательного обозначения (перифраза), характеризующийся сгущением семантического содержания в одном слове и утратой формального членения» [7, С. 108].

Согласно К. Леманну, универбация - это синтагматическая конденсация последовательности слов, повторяющихся в дискурсе, в одно слово. Кроме того, автор выделяет два основных типа универбации: фразовая и трансгрессивная универбация. Первая понижает фразу до слова, а вторая объединяет в слово ряд слов, не образующих синтагму [8, с. 1$]$.

Тот факт, что у универбации нет единого, устоявшегося и единогласно признанного названия, доказывает, что универбация не является хорошо изученным лингвистическим явлением в английском языке.

Результатом универбации считается слово "универб", имеющее синонимичное словосочетание. Н.А. ЯнкоТриницкая называет универбы словами с включением, понимая под включением расширение значения слова, осуществляемое за счет семантики другого слова, которое не получает в этом слове самостоятельного морфемного выражения [9, С. 385].

Н. В. Дьячок утверждает, что универб - это отдельное слово, грамматически тождественное исходному словосочетанию, отличающееся от него стилистическими оттенками разговорности и сленгизма [10, С. 145].

Т.Н. Буцева и О.М. Карева, в свою очередь, определяют универбы как единицы вторичной номинации, суть которой заключается в том, чтобы дать новое название предмету, который уже был назван [11, С. 174]. Следовательно, можно предположить, что универб - это замена синтаксической фразы одним словом.

Исходя из вышесказанного, можно сделать вывод, что универбация на лексическом уровне представляет собой компрессивный способ словообразования, результатом которого является универб, структурно более короткий, но семантически идентичный исходному словосочетанию.

Появление новых слов, значительно пополняющих словарный запас английского языка, который, как известно, является самым большим в мире, традиционно объясняется следующими тремя источниками: 1. заимствования из других языков; 2. многочисленные способы словообразования; 3. полисемия. Словообразование единогласно признается самым богатым источником новых слов трех различных структурных типов: простых, производных, сложных. Претерпев значительные изменения в ходе своего исторического развития, английская словообразовательная система в настоящее время демонстрирует большое разнообразие способов словообразования. Стоит отметить, что в связи с пристрастием англичан к краткости высказываний, английская словообразовательная система также разработала ряд способов построения слов, сокращающих структуру слова, таких как конверсия, сокращение, включающее аббревиацию, блендинг. Эти способы можно с полным основанием назвать компрессивными, поскольку их характерной чертой является сжимающая сила, учитывающая структурное сокращение лексемных и фразеологических единиц языка.

XXI век характеризуется ускорением ритма общественной жизни, ростом социальных процессов, а также удивительными изменениями в развитии языка в целом и лексики в частности. Нельзя не обратить внимание на обильный рост новоиспеченных слов как на страницах прессы, в средствах массовой информации, так и в повседневном общении. Компрессия играет в этом процессе самую активную роль, а проявляясь в универбации, приобретает первостепенное значение в формировании особенностей публицистического стиля, поскольку сокращение объема текста вряд ли может обойтись без языковой компрессии. Именно компрессия уменьшает количество структурных компонентов слов, словосочетаний и предложений в передаваемом тексте, а также оказывает существенное влияние на содержание, восстанавливая исходную структуру. В процессе перестройки сжатые компоненты «передают» свои функции несжатым компонентам, функциональная нагрузка которых становится иной по сравнению с их ролью в полной, несжатой форме речевой единицы.

Так, аббревиатура в английском языке имеет долгую историю. В рукописях копий древнеанглийской поэмы «Беовульф» использовалось множество сокращений, например, '7' или '\&' для 'and,' 'y' для 'since', чтобы «не тратить много места» [12; с. 57]. Актуальность данного метода определяется необходимостью компактно называть новые понятия и объекты. Целесообразность заключается в создании предельно экономичных и семантически емких номинативных единиц.

Следовательно, аббревиация призвана обеспечить передачу максимального количества информации (семантического содержания / плоскости содержания) при минимальном использовании материальной оболочки языка (звуковой оболочки и графической формы), то 
есть повысить эффективность коммуникативной функции языка.

В английском языке существует 3 типа аббревиации:

1. Инициализмы - это сокращенные слова, образованные с помощью начальных букв многосложных слов, сложных слов и фраз, например: AT\&T (American Telephone and Telegraph), KFC (Kentucky Fried Chicken), IBM (International Business Machines), MP (Member of Parliament), NHS (National Health Service).

2. Акронимы - это слова, которые изначально были аббревиатурами, но со временем стали самостоятельными. Акроним образуется из первых букв группы слов. Мы произносим акроним как слово, например: NATO (North Atlantic Treaty Organization), D.A.R.E. (Drug Abuse Resistance Education), SAD (Seasonal Affective Disorder), AMMO (Aircraft Munitions Maintenance Organization).

3. Гибридные сокращения - представляют собой замену начальной буквой только первого элемента сложного слова или словосочетания, в котором второй элемент не изменяется: $b$-day (birthday), b-ball (basketball), h-bomb (hydrogen bomb). По мнению К.В. Филиной [13, 148 с.] гибридные аббревиатуры могут появляться и в том случае, если первый элемент сочетания является сокращением всей фразы, а второй элемент представлен полным словом, например, Epcot Center, где Epcot - Experimental Prototype Community of Tomorrow.

Одним из наиболее интересных методов словообразования является телескопическое словообразование или блендинг. Блендинг - это способ словообразования, представляющий собой слияние двух или более усеченных стволов или слияние полного ствола с усеченным, в результате чего образуется новое слово, полностью или частично сочетающее в себе значения всех входящих в него структурных элементов. Современные СМИ наглядно демонстрируют, что сегодня английский язык переживает «неологический бум», что дает повод считать, что блендинг становится одним из самых продуктивных и частых способов построения новых слов, например: spork (spoon + fork), Spanglish (Spanish + English), moped (motor + pedal), smog (smoke + fog), frenemy (friend + enemy), emoticon (emotion + icon), Oxbridge (Oxford + Cambridge), brunch (breakfast + lunch), Bollywood (Bombay + Hollywood), cosplay (costume + play), biopic (biography + picture), hangry (hungry + angry).

Изучением блендинга занимались многие российские и зарубежные лингвисты. Первые попытки были предприняты в XIX в. Г. Паулем (1880) и Г. Свитом (1892). В XX в. появилось много научных работ, связанных с исследованием блендинга, среди них исследования Т.Р. Тимо- шенко (1976), Алгео (1977), А.У. Мурадян (1978), У.А. Жлуктенко (1983), Л.А. Тарасовой (1991), Н.А. Шехтман (2003), Е. Томашевич (2008), О.А. Хрущева (2011) и др.

Считается, что с конца XIX века термин «portmanteau word», введенный Л. Кэрроллом, является предпочтительным в Великобритании. В американском английском языке термин «blend» был впервые введен в 1883 году и с тех пор широко используется.

Г. Кэннон рассматривает блендинг «как явление, когда два синонимичных предмета одновременно проникают в сознание, создавая тем самым новую форму, в которой элементы одной формы смешиваются с элементами другой, что проявляется частично в фонетической форме отдельных слов и частично в их синтаксическом сочетании» $[14$, с. 284$]$.

Другим компрессивным методом, приводящим к образованию универбов, является конверсия. Конверсия на современном этапе развития лингвистики понимается как способ словообразования без использования специальных словообразовательных аффиксов; разновидность транспозиции, при которой переход слова из одной части речи в другую происходит таким образом, что исходная форма слова одной части речи используется без существенного изменения как представитель другой части речи [15, с. 33]. По мнению А.И. Смирницкого, конверсия - это образование нового слова путем изменения его парадигмы [16, с. 56]. Конверсия как способ словообразования глаголов и существительных стала одной из характерных черт английского языка с XIII в. Известно, что она возникла в результате распада инфлективной системы языка в начале среднеанглийского периода.

Рассматривая конверсию в аспекте универбации, можно отметить, что при конверсии лексические единицы универбы - не только приобретают новое значение, но и получают новую парадигму и синтаксические функции.

Так, существительное dust путем конверсии преобразуется в глагол to dust, семантическое значение которого передается фразами to cover with dust, to take off the dust, но благодаря принципу универбации эти семантические значения передаются одной лексемной единицей to dust, имплицитно выражающей значение to cover with dust или to take off the dust.

Конверсия, безусловно, является важным инструментом, с одной стороны, для расширения словарного запаса английского языка, а с другой - для экономии речевых усилий и языковых средств в процессе общения.

Тщательный анализ выборки универбов, извлеченных из статей различных английских местных, регио- 
нальных, условных, ежедневных и еженедельных газет, позволяет подтвердить активное функционирование универбов в языке современной прессы, проследить продуктивность словообразовательных тенденций, связанных с универбацией как одной из ипостасей компрессии.

Существование универбов справедливо свидетельствует об креативном факторе в английском языке. Газеты заинтересованы в таких словосочетаниях, потому что они позволяют им привнести креативность в свои произведения, что, соответственно, добавляет элемент интересности в их литературные тексты. Более того, это привлекает внимание читателей, поскольку они наслаждаются и ценят эту тонкую демонстрацию игры слов. Кроме того, средства массовой информации часто справедливо считаются одним из источников универбов.

Подводя итоги исследования, можно сделать следующие выводы:

1. В результате лексической компрессии возникают явления универбации и универб. Первое - это процесс сокращения и упрощения либо структуры синтаксических единиц, либо полисиллабических слов. Второе - продукт универбации, характеризующийся краткостью, минимальной формальной структурой, но содержащий полный объем необходимой информации.

2. Термин «универбация» восходит к латинскому слову «unumverbum», что означает «одно слово», и впервые был использован в 1904 году, а затем развитие теории универбации было положено в 70-80-е годы прошлого века. В настоящее время теория универбации тщательно изучается многими лингвистами. Результатом универбации считается слово «универб» - синонимичное словосочетание, определение которого до сих пор является спорным вопросом.

3. Результаты комплексного анализа функционирования основных видов лексической компрессии в английской прессе свидетельствуют о прямом влиянии социального аспекта, исторического развития английского общества и английской прессы на эволюцию и особенности употребления лексической компрессии в английском языке.

4. Универбы, обозначающие новые социальные явления и процессы, теряют статус окказиональных лексических единиц, включаются в словарный состав английского языка и фиксируются словарями.

ЛИТЕРАТУРА

1. Валгина, Н.С. Активные процессы в словообразовании; М. 2001. 304с.

2. Копоть Л.В. Универбация как вид компрессивного словообразования в современном русском языке; Майкоп; 2001. 210 с.

3. Осипова Л.И. Активные процессы в современном русском словообразовании; М. 1994. 251с.

4. Алефиренко Н.Ф. Фразеология и паремиология; М.; 2009. 344 с.

5. Гудилова С.В. Реализация закона речевой экономии на примере универбации; Ульяновск; 2012. 28 с.

6. Докулил М. Словообразование в чешском языке; Прага; 1962. 263 с.

7. Ахметжанова 3.К. 0 процессе универбации; Алма-Ата; 1977. 117 с

8. Lehmann Christian, Univerbation; Erfurt; 2020.36 p.

9. Янко-Триницкая Н.А. Словообразование в современном русском языке; М. 2001. 503с.

10. Дьячок Н.В. Этапы формирования явления универбации в русском языке; Киев; 2012.148 с.

11. Буцева Т.Н., Карева 0.М. Русская академическая неография; СПб. 2006. 236

12. Elly van Gelderen, A History of the English Language: Revised edition; Arizona State University; 2014. 337 p.

13. Филина К.В. Основы терминоведения. Новосибирск, НГУ, 2013.174 с.

14. Cannon Garland, Blends in English word formation; Berlin; 1986.753 p.

15. Кубрякова Е.С., Гиреев В.А. Конверсия в современном английском языке; Воронеж; 2002.38 с.

16. Смирницкий А.И. Лексикология английского языка; М. 1956. 260 с.

(с) Конев Роман Евгеньевич (konevre@mail.ru).

Журнал «Современная наука: актуальные проблемы теории и практики» 